This item was submitted to Loughborough's Research Repository by the author.

Items in Figshare are protected by copyright, with all rights reserved, unless otherwise indicated.

\title{
Learning to adapt health and safety initiatives from mega projects: an Olympic case study
}

PLEASE CITE THE PUBLISHED VERSION

http://www.ingentaconnect.com/content/iosh/pphs/2012/00000010/00000002/art00006

PUBLISHER

(C) IOSH Services Limited

VERSION

VoR (Version of Record)

LICENCE

CC BY-NC-ND 4.0

\section{REPOSITORY RECORD}

Finneran, Aoife, Ruth Hartley, Alistair G.F. Gibb, Alistair Cheyne, and Phillip D. Bust. 2019. "Learning to Adapt Health and Safety Initiatives from Mega Projects: An Olympic Case Study". figshare.

https://hdl.handle.net/2134/12747. 
This item was submitted to Loughborough's Institutional Repository (https://dspace.lboro.ac.uk/) by the author and is made available under the following Creative Commons Licence conditions.

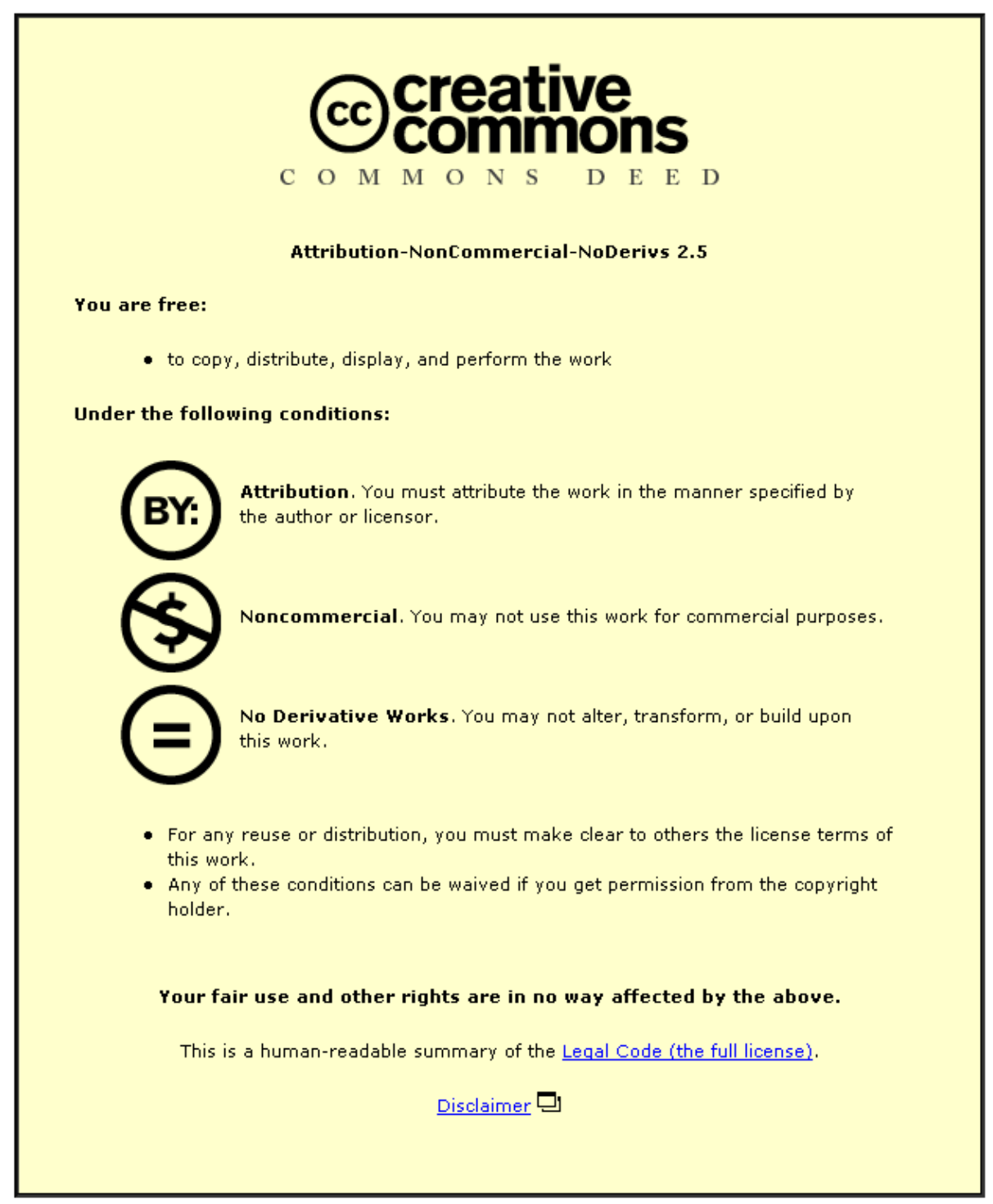

For the full text of this licence, please go to: http://creativecommons.org/licenses/by-nc-nd/2.5/ 


\title{
Learning to adapt health and safety initiatives from mega projects: an Olympic case study
}

\author{
Aoife Finneran BEng PhD MIES, Ruth Hartley BSc MSc, Alistair Gibb BSc PhD CEng \\ MICE MCIOB, Alistair Cheyne BA MA PhD CPsychol and Phil Bust BEng MSc PhD MIEHF, \\ Loughborough University, UK
}

\begin{abstract}
Finding new ways to improve health and safety management in construction continues to generate much interest. Despite a reduction in deaths, injuries and ill health in recent years, UK construction still has high rates of fatal and major injuries compared to other industries. One of the key concerns is the difficulty of organisational learning in construction manifested as reactive responses to health and safety issues. The Olympic Delivery Authority launched a learning legacy programme in conjunction with industry, government and academia to capture important lessons learnt in a number of areas, including health and safety. Communication has long been considered an important factor in the implementation of health and safety initiatives. Previous research has typically focused on programmes run by single organisations. The London 2012 Olympic Park construction project offered a unique opportunity to investigate the impact of safety initiatives and communication across a range of organisations working side by side. It also offered an exciting opportunity to track health and safety messages as they are communicated to the workforce.
\end{abstract}

The main aim of this research project was to evaluate the range of health and safety initiatives used at the Olympic Park in terms of messages communicated to workers, workers' awareness, attitude and behaviour, and the transfer of knowledge within and outside the Park. A semistructured inventory was used to survey the workforce (managers, supervisors and workers) using interviews and focus groups on seven Park sites. A follow-up survey was conducted after three months, at which time interviews and focus groups were also held at non-Olympic comparison sites. Data were also collected through the observation of meetings and document review. The data were analysed using template analysis in line with the communication-human information processing (C-HIP) model.

The transfer of knowledge into and out of the Olympic Park, and the impact of the communication processes on workers, were key issues identified from the analysis. The results were used to produce industry recommendations that are applicable beyond the realm of a mega project. Important recommendations include, but are not limited to, the important role of the client, the need for planning and the focus on workers' comprehension and safety behaviour. The most important recommendation was that methods used at the Olympic Park should be used on more traditional projects.

\section{Key words}

Communication, health and safety, learning legacy

\section{Introduction}

In spite of recent improvements, the term 'safe construction' is, in itself, an oxymoron: construction sites are inherently dangerous. In fact, construction is noted as one of the most 
hazardous industries globally. ${ }^{1}$ The figures speak for themselves: in 2009/10 construction accounted for 4 per cent of all employees in Britain, but 7 per cent of reported injuries to employees (27 per cent of fatalities; 10 per cent of major and 6 per cent of over-three-day injuries). ${ }^{2}$ This begs questions such as: why is construction so dangerous, and what can be done to improve health and safety on construction sites?

At a higher level, several authors have attributed poor health and safety performance in the construction sector to the difficulty of organisational learning. The construction sector is unique, in that any project calls for the involvement of multiple contractors, trades and professionals, who typically disband at the completion of each project. A transient workforce ${ }^{3,4}$ of project personnel from different cultures and backgrounds are expected to work together in a constantly changing work organisation and structure. Furthermore, the uniqueness of each project means there is less likelihood of changing a controlled process one step at a time, as is the case in manufacturing. ${ }^{5}$ The reality is that while construction solutions are often pragmatic, by virtue of the uncertainty of the environment, they are also reactive. From a health and safety point of view this is problematic, as the goal is to stop incidents occurring in the first place.

The apparent one-off, non-routine projects and tasks in the construction industry imply that organisational learning is considered a daunting task. However, Davies \& Brady ${ }^{6}$ propose a different view:

Performance in the construction industry can be improved through exploitative learning because firms undertake 'similar' categories of projects which involve repeatable and predictable levels of activity.

If projects are viewed as unique entities and not systems that require similar skills, utilities and expertise for their execution, we could conceal many potentially transferable lessons. ${ }^{7}$ It would appear that lessons can be learnt from construction projects, as long as there is an organised medium of communication. This level of organisation and resource may be difficult to attain for small and medium-sized enterprises, which already work to tight completion deadlines and with scarce resources. ${ }^{8}$ However, mega projects with sustained budgets and substantial resources have the ability to capture lessons learnt. These projects are an important medium to pass on lessons to the rest of the industry.

With the substantial development of an impoverished London suburb, the construction of several major sports venues, an integrated transport network, infrastructure and employment programme, the London 2012 construction project easily falls under the remit of a mega project. The Olympic Delivery Authority (ODA) was the public body responsible for building and developing the Park, the venues and its infrastructure for use during the games and beyond 2012. The ODA realised the importance of organisational learning and, to capture the lessons learnt from the London 2012 construction project, they worked closely with contractors, industry partners, government bodies and academia to document these lessons, innovations and best-practice examples across 10 Learning Legacy themes, ${ }^{9}$ including health and safety.

Health and safety in the construction industry is a complex issue and there are many factors leading to the causation of ill health and accidents. Hide et al. ${ }^{10}$ propose that causation can be described by a number of hierarchical influences and that accidents arise from the failure in the interaction between the work team, workplace, equipment and materials. The complex 
nature of organisational interactions means that workers might receive information from a number of different sources, and it has been suggested that they learn to adapt their behaviour depending on the group or culture they identify with. ${ }^{11}$ Several authors ${ }^{12-14}$ suggest that the implementation of successful safety programmes relies on the participation of management and workers, and the development of a feedback system to drive continual improvement. Worker engagement and communication are important drivers in the success of health and safety programmes. ${ }^{12}$

The current research project evaluated the effectiveness and impact of safety communications during the construction of the facilities for the London 2012 Olympic and Paralympic Games. Links between safety programmes, health and safety communication systems and the actual state of safety have been studied extensively, ${ }^{15-17}$ but typically focus on programmes run by single organisations. The Games' construction project offered a unique opportunity to investigate the impact of safety initiatives and communication across a range of organisations working side by side. It also offered the opportunity to determine good practice in terms of communicating health and safety messages effectively through construction projects to the workforce. This information is useful for a wide range of organisations working in this industry and has application beyond large construction projects.

The following section is included to give the reader a contextual view of the site organisation. To carry out the works, the ODA engaged CLM (the delivery partner), a consortium made up of three organisations: $\mathrm{CH} 2 \mathrm{M}$ Hill, Laing O'Rourke and Mace. The various infrastructure projects and venues were managed by Tier 1 contractors. Within each site there were subcontractor tiers (Tier 2 and Tier 3). The ODA and CLM communicated directly with Tier 1 contractors, who then forwarded messages to the subcontractors within their site. Typically, the workers were employed by subcontractors. Sites were run exclusively by the principal contractor, with the ODA and CLM offering direction, monitoring, framework, guidance and reprimand. Figure 1 highlights the flow of communication between the actors involved in the project.

The achievements in health and safety at the Olympic Park (OP) were outstanding. The latest available incidence of reportable non-fatal injury for UK construction (2008/09) is around 1,300 per 100,000 workers (three-year average), ${ }^{2}$ equating to an accident frequency rate (AFR) of at least 0.75 (number of reportable accidents $\mathrm{x} 100,000$, divided by the number of hours worked, assuming 40 hours per week and 50 weeks per year). The AFR at the OP was 0.165 , which is around 22 per cent of the UK average for construction, or more than 4.5 times better. The sheer scale of the achievement in terms of health and safety at the OP highlights the lessons that could be learned by construction projects more generally.

Contractors followed a series of compulsory common standards to run their sites. While the contractors had to meet the demands of each standard, they were given freedom in how to achieve them. The advantage of this was that contractors implemented objectives to suit their projects. The ODA also provided support to inexperienced contractors by organising monthly meetings at which all contractors had the opportunity to communicate with their counterparts to aid continual improvement, share innovation and highlight issues before they became problems on other sites.

While communication is an important asset used by the many site actors involved in construction projects, this research was interested specifically in the efficacy of health and safety communication. Many models describe the communication process; for the purposes of 
this research, Conzola $\&$ Wogalter's ${ }^{18}$ communication-human information processing (C-HIP) model was considered to offer a systematic representation of the communication process and was used as a basis for evaluating the efficacy of health and safety communications at the Park. This model is based on communication theory and is designed specifically to address the communication of health and safety information. The model goes beyond the understanding of information, recognising the importance of attitudes/beliefs, motivation and, ultimately, the impact of communication on safety behaviour. Safety communication must pass through a number of stages to successfully impact on behaviour. The basic stages relate to the source of the communication (for example, supervisor), the channel used, and the receiver of the communication (typically the worker). Figure 2 outlines the model and the flow of information within it. If information is blocked, at any stage, this can have negative consequences for safety behaviour.

Figure 1

Communication at the Olympic Park (adapted from Bust $\left.{ }^{19}\right)$

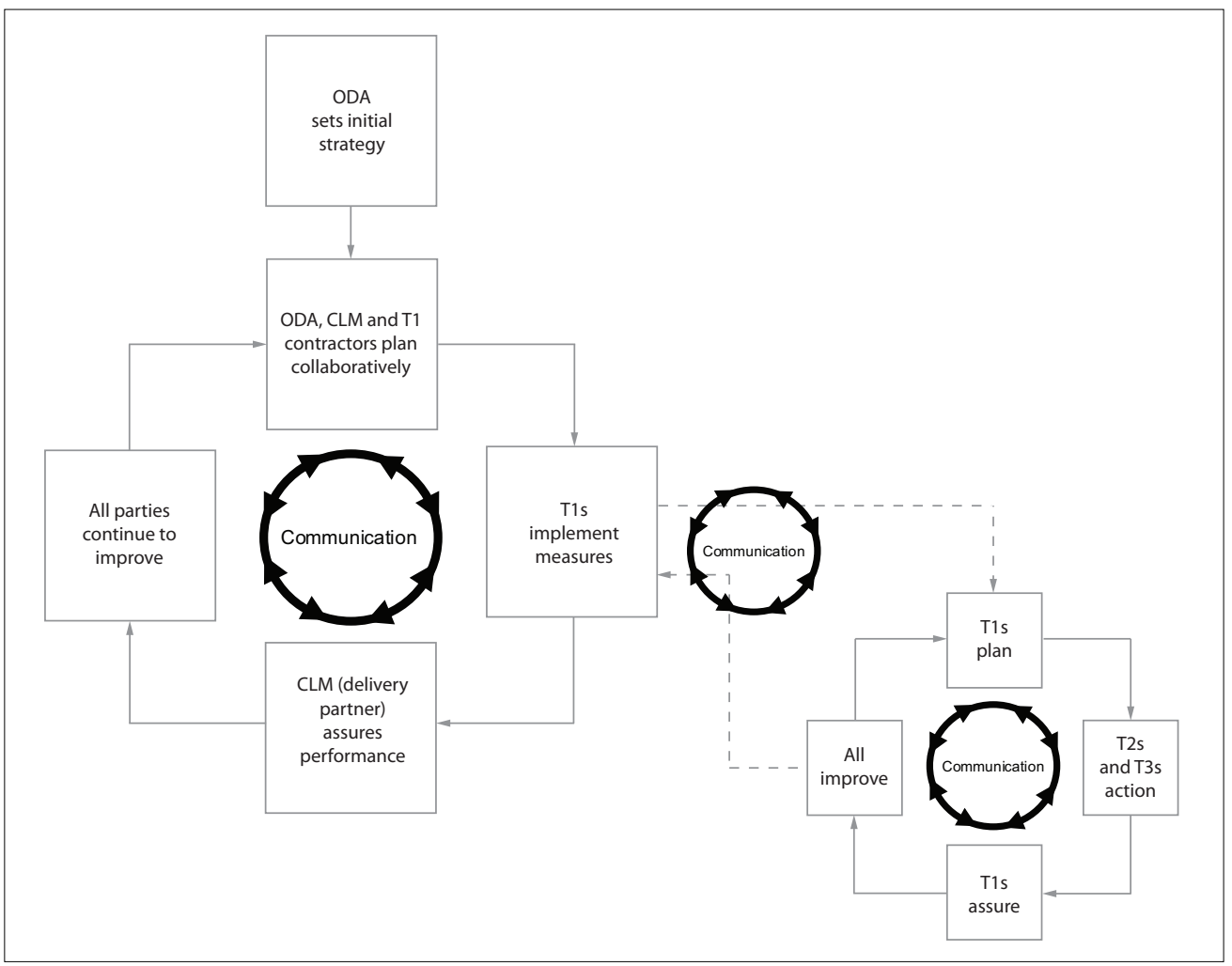

Figure 2 C-HIP model (adapted from

Conzola \& Wogalter ${ }^{18}$ )

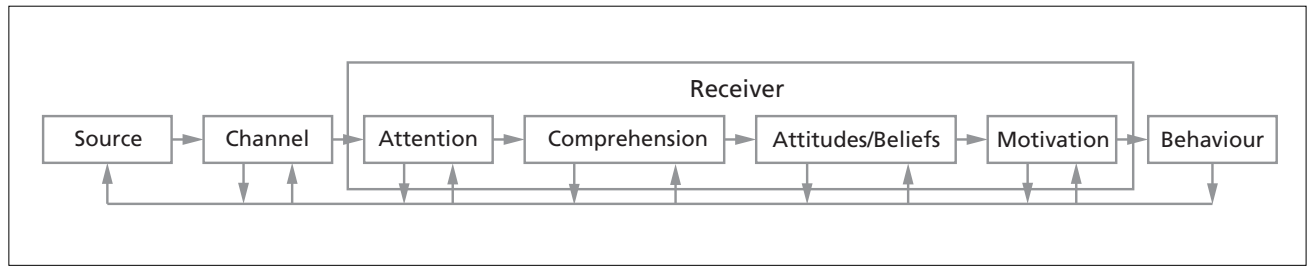




\section{Research aims}

The main aim of the communication research project was to evaluate the efficacy and impact of health and safety initiatives taking place at the OP development site, including:

- the processes by which the main hazards and safety messages were communicated to workers at the OP

- individual workers on site - awareness, attitudes and behaviours

- cross-contractor learning - initiative implementation, including transfer of good practice at the OP to external contractor sites.

\section{Study design and methodology}

Research interviews and focus groups were conducted with OP contractors at two main stages: 'Time 1' and 'Time 2'. Interviews were also conducted with senior ODA/CLM managers. Concurrently, additional data were collected via direct observations of meetings and document reviews. Semi-structured inventories were used for both interviews and focus groups. At Time 1, inventory questions were designed to address each of the C-HIP stages, to determine the effectiveness at each stage. Later, additional themes were added. Preliminary analyses were undertaken between data collection at Time 1 and Time 2, and inventories for Time 2 were amended to focus on emergent themes and issues, and determine the successful transfer of safety messages. At Time 2, broader questions were asked about factors which facilitated the communication process and specific questions were posed to track particular campaigns and messages across the Park. At Time 2, interviews and focus groups were also conducted at comparison non-Olympic sites. The initial research design proposed a 12-month break between Time 1 and Time 2 data collection - the construction period. This would have made it possible to assess how initiatives instigated nearer the beginning of the project had been implemented in practice. However, due to restrictions, Time 1 data collection commenced six months later than envisaged. Additionally, there was a phased completion of the various construction projects, ie venues were completed sequentially rather than concurrently. Therefore, in order to obtain data prior to project completion, some Time 2 data collection commenced after a three-month break.

\section{Sample}

Access to interviewees and focus groups was arranged by the ODA's Learning Legacy Team. As a result, participants were not randomly sampled.

\section{ODA and CLM senior managers}

A selection of senior ODA and CLM managers were interviewed and chosen based on their expertise in relation to the research aims. Twelve people were interviewed in this category.

\section{Games contractors}

Access to Games contractors was mediated by the ODA Learning Legacy team. Sites were selected to provide a mix of infrastructure and venues contractors (permanent and temporary). Interviews were requested with:

- the project director

- the project manager

- the health and safety manager

- a manager with health and safety responsibilities

- two subcontractor managers (typically Tier 2 or 3)

- two supervisors. 
Sites were asked to arrange two focus groups with operatives. On busy sites, it was not unusual for people to be unavailable, or for only one focus group to be available. The ambiguity of the term 'supervisor' meant that a wide variety of people were interviewed with this generic title. Those interviewed varied in terms of whether they were employed by the principal contractor or subcontractor, and according to their relative seniority in the contracting structure, eg some supervisors were directly employed by the contractor and had responsibility for subcontractors' supervisors.

At Time 1, 53 interviews and eight focus groups were conducted, with 57 workers taking part in focus groups. At Time 2, 42 interviews and nine focus groups were conducted. In total, 49 workers took part in these latter focus groups. At both Time 1 and 2, workers varied in terms of trade, experience in the construction industry, and time at the OP. The vast majority were male.

\section{Comparison sample}

Twenty three interviews (site managers, health and safety managers, and supervisors) and focus groups ( 39 operatives) were conducted at six sites elsewhere in the UK with two contractor organisations.

\section{Validity and reliability}

Random sampling was not used; therefore, there is the potential for bias in site and participant selection. It is possible that sites and participants were selected because they were deemed to be better at, or have a more positive attitude to, health and safety communication. However, although much of the data obtained was positive, a number of negative aspects were identified. It seems plausible that a realistic assessment of communication has been obtained.

\section{Data analysis}

Data were analysed with NVivo 9 software using a template analysis. ${ }^{20}$ An initial coding frame was developed based on the research aims and C-HIP model. The coding was added to as themes emerged and data analysis progressed. The researchers identified pertinent themes or issues, which were assigned a code. The codes were organised to show the relationship between themes, typically hierarchical relationships.

\section{Main findings}

The objective of this paper is to provide recommendations for various sized organisations within construction to improve their communication of health and safety, rather than highlight the overall findings related to communication. For further information, the reader is directed towards the final project report ${ }^{21}$ and a 3,000-word summary document available on the Learning Legacy website. ${ }^{22}$

\section{Key recommendations (pertinent results) and discussion}

The recommendations (see Table 1) are highlighted for their transferability beyond the OP to organisations of various sizes. The key recommendations were a result of initial template analysis of the themes found in the data. A preliminary coding frame was developed based on the research aims, the C-HIP model of communication, ${ }^{18}$ facilitating and enabling factors (that emerged at Time 1), and message transfer for reactive and proactive communications (document analysis). This initial template was developed and refined as data were analysed and new codes emerged. The coding templates were assessed and verified by a panel of industry and academic experts. 
Each recommendation is categorised according to its relevance under the C-HIP model. It should be noted from this model that all aspects of communication are interrelated.

Therefore, while Table 1 shows which part of the model is influenced most by the different recommendations, each initiative will affect all parts of the process to some degree. As the data developed, sector experts verified the strength of relationships (initially established through frequency) and proposed a numeric coding frame, where greater numbers signify stronger relationships. The relevance of each factor to organisational size was based solely on the opinion of the expert panel.

The ultimate aim of all health and safety communication is to reduce the incidence of accidents and ill health. Once design and pre-construction risk elimination and reduction has been completed and all appropriate engineering and protective controls have been applied, this is achieved primarily by improved health and safety behaviours.

\section{Recognise significant client role}

The importance of the client role in construction has been an important focus for many years. ${ }^{23-26}$ At the OP, the client was cited as one of the major factors for the success of health and safety, in line with the government-driven vision to deliver a safe and secure build with no fatalities. The ODA, as with all clients, had a moral, legal and ethical responsibility for the safety of its project. ${ }^{18}$ The success of health and safety at the OP was attributable, in part, to the client's vision to hire competent and capable contractors and designers. However, the reality is that a commitment to safety and the employment of competent staff falls under the remit of the client's legal obligations. ${ }^{27}$ As this is the case for every construction project, then why was the client on this project such an important driver for safety? It would appear that the client genuinely wanted a safe and healthy workplace, with zero fatalities. And in the world of construction, what the client wants, the client gets - but they really have to want it:

We've got what we wanted here. It could be even better, but at the minute it's really pretty good. So any client on any job could get what we've got here if they wanted it. They just need to want it. (Senior CLM staff)

There is general agreement in the literature over the important role of the client in establishing, driving and maintaining a safe and healthy environment. Lingard \& Rowlinson ${ }^{28}$ argue that health and safety in construction could learn a lot from quality management systems that are largely client driven, because quality is a major indicator of a project's success. An interest in occupational safety and health on the part of the client may be the best way to ensure that it is integrated into the business process. Indeed, some authors argue that health and safety complements a client's cost, quality and time requirements. In fact, a successful project is often a healthy one..$^{29}$ Industry is also in agreement about the importance of the client in driving health and safety. An $\mathrm{HSE}^{30}$ document highlights how industry professionals have a key responsibility to influence client commitment to health and safety. The London 2012 construction project was successful because the client insisted on high health and safety standards. Their initial planning and organisation meant they could provide direction (source/channel) and a key leadership (feedback) role to contractors and employees.

\section{Lead from the top}

The ODA was a focused client who gave direction and showed contractors what they wanted to achieve by using standards to remove ambiguity and help contractors focus on their goals. In effect, the ODA was a good leader. The definitions associated with leadership are invariably ambiguous, while the terms 'leadership' and 'management' are often used 
interchangeably. However, managers often focus on short-term goals and solving problems in the here and now to keep a company going. Leaders, on the other hand, use many of the softer skills: they direct and motivate, have the vision to change behaviour, and focus on the horizon. In most cases, managers are appointed whereas leadership is earned. ${ }^{31}$

Dainty et al. ${ }^{32}$ regard leadership as one of the major factors contributing to a project's success. Moreover, one of the pertinent themes running through the central health and safety strategy for Great Britain is leadership. ${ }^{33}$ Levitt $\&$ Samelson ${ }^{34}$ state that a leader who believes in safety gives direct evidence of this by holding managers accountable for the safety of their subordinates, and a willingness to commit to real and sustained training resources. In doing so, training can be more effective and there can be a detailed pre-planning of work. Leadership has a particular influence on the communication source, channels and feedback, and is important for all projects, irrespective of their size.

Table 1
Summary
recommendations
relating to
communications
and users

Recommendations beyond London 2012

Recognise significant client role Lead from the top Appoint a delivery partner Provide credible sources Set the standards

Plan ahead

Choose effective channels and attention Develop communication context Develop competent supervisors Improve comprehension Stimulate attitudes and beliefs Foster motivation to behave safely Foster an open, positive safety culture Reward good behaviours Co-ordinate communication systems Stimulate cross-contractor learning Review and learn Provide assurance
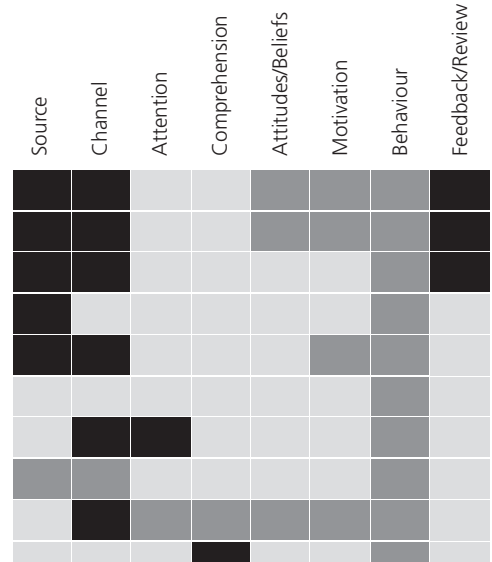$$
\text { . }
$$$$
\text { . }
$$

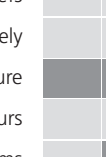

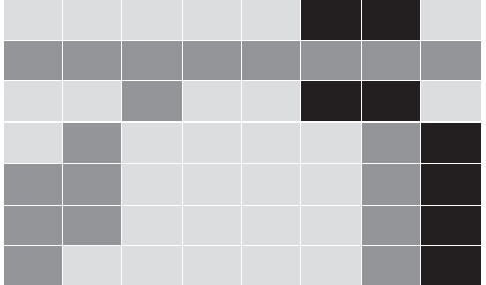

Relevance for:

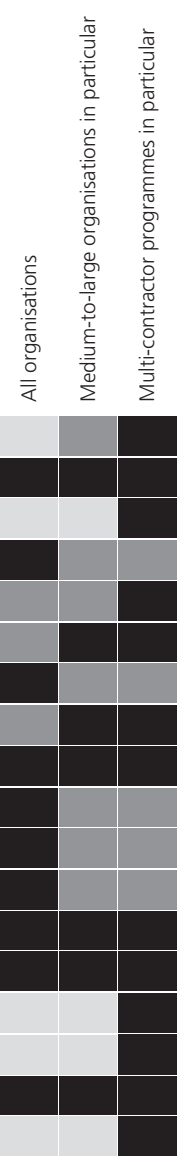




\section{Appoint a delivery partner}

In the context of mega projects, delivery partners are private consultants who act on behalf of the client in project delivery; they are not directly involved in the construction process. However, they are often major contractors who have considerable expertise in project delivery. In general, the added expense of a delivery partner yields better results. ${ }^{35}$

The importance of the delivery partner working with the client was also highlighted. It was felt that the delivery partner helped shape the dreams and aspirations of the client into reality.

From the C-HIP model perspective, the delivery partner influences source, channels and feedback. The presence of a delivery partner will influence multi-contractor projects in particular:

The ODA set standards. These are something that we would recommend as a delivery partner and say, you know, 'What does everyone think?', or we do it in collaboration with the Tier 1s and develop that best practice. (Assurance team member, CLM)

\section{Provide credible sources}

Consideration should be given to the credibility and competence of the source. The credibility of a message source is directly related to the effectiveness and persuasiveness of a message. ${ }^{36}$ Credibility reduces the likelihood of stress to the message recipient. ${ }^{37}$ Credibility can be enhanced in a number of ways. In this context, experience of the construction industry is helpful but not essential. Health and safety managers achieved credibility through the relationships they established with the workforce. Credibility grows as the workforce is engaged.

\section{Set the standards}

The client can influence health and safety practice significantly by clearly stating their expectations before a project starts. Not following set standards and procedures can greatly affect project quality and performance. ${ }^{38}$ As a client, the ODA showed considerable direction and gave guidelines to contractors from the start, to avoid ambiguity and create common goals. Additionally, common standards were set, over the duration of the project, as a benchmark for what the contractors had to achieve. Some uniformity was needed on site so that everyone could work towards the same goal of zero harm and employee safety:

Standards are developed in collaboration with contractors. Most are easily implemented because they are benchmark setting; they are framework standards, not prescriptive ways of delivering. We let them decide... We've tried to be aspirational, not prescriptive in our goal setting. (Assurance team member, CLM)

The standards set by the ODA were seen as tough but achievable. Contractors appreciated the way that standards were provided as an autonomous guide, alongside support and powers of reprimand:

I think the ODA have set very tough but achievable targets in relation to performance, and also across the whole sort of 'respect' agenda and the whole 'opportunities' agenda with apprentices. (Tier 1 director)

As the programme continued, more standards were developed to assist and progress contractors' work. The ODA worked with contractors to develop these standards and facilitate their implementation: 
The ODA standards for health and safety and environment in design and construction... were part of the contract. We had a group of common standards when we first started that were sort of developed over the years and we've also added some more to them... and they're subject-specific... The intention of them was to [be] over and above normal practice or best practice to set a new standard for what we want on Olympic Park. (Assurance team member, CLM)

The standards also helped contractors develop their subcontractors and clarify exactly what was expected of them:

We've got to set those standards very clearly up-front so people do understand what is expected and then we can get on with it. That's all part of learning at the beginning usually with a subcontractor or our own people. (Tier 1 project director)

At the procurement stage, the ODA and CLM were aware that not all of the contractors were at the same level of competence, nor had they all implemented the prescribed training programmes. To remedy this, CLM placed contractors on a behavioural matrix so that each contractor could get support specific to their requirements:

We asked them questions that could measure where they sat on a behavioural matrix so they could position themselves and then you give them the guidance to the next step. Giving them that framework allowed them to see what they needed to do next to improve... it's not about standing still; it's about moving and associated reward and recognition. (Senior CLM staff)

Setting strategies and maintaining them is important on all projects. However, there is a particular need to set strategies on large and more complex projects. Setting standards has a particular influence on the communication source and channels.

\section{Plan ahead}

Planning was an important theme from the beginning of the OP construction project. The layout and organisation of the Park worked to the OHSAS 18001 Standard methodology known as 'plan-do-check-act'. Moreover, it was believed that planning ensured that expectations could be met so that any issues were eliminated or accommodated before they got 'out of control':

... we wanted to manage everybody's expectations so that we didn't keep moving into disaster zone. Everything's well planned for. It's still moving at pace. It doesn't hold you back; you're trying to keep one eye on the future and one eye on the present. (Senior CLM staff)

Effective planning is crucial for the success of any construction project. ${ }^{39}$ However, planning can also contribute to the prevention of accidents and ill health on site..$^{40,41} \mathrm{~A}$ coordinated effort between planning objectives and health and safety can not only improve the health of the workers, but also the cost of the project. ${ }^{42}$ Planning ahead has important implications for health and safety at a number of levels. Planning allows risks to be identified and communication campaigns developed to address them. Well-planned activities are easier to communicate effectively through the selection of the most appropriate channels. Developing systems which encourage subcontractors and supervisors to plan and co-ordinate their work is also beneficial in terms of minimising the number of 
different trades working in the same area and reducing conflict. Planning ahead is crucial for all projects, particularly larger and more complex ones, and generally influences the channel and context of communication.

\section{Choose effective channels and attention}

Different channels are more effective at gaining individuals' attention. Ideally, a blend of channels should be used to reinforce a message. Interviewees indicated that the primary medium of communication should be verbal. It would appear that in the fast-paced construction industry, the spoken word is the quickest and most effective way to get a message across. Moreover, verbal communication has benefits for worker engagement, as long as the worker is given the opportunity for feedback. However, there is concern in the literature over the use of the spoken word as the primary source of communication on site. Dainty et al.$^{43}$ highlight that while verbal communication may appear straightforward, there are inherent negative implications. The industry is very fragmented, which implies that the appropriate actors may not be present when the message given. Moreover, a paper trail is needed to take note of accountability and feedback into the learning-planning cycle. Construction sites are generally noisy, which can make it difficult for workers to hear verbal advice given to them. If verbal communication is to be used, it is imperative that the environment is suitable to relay the message. A further concern is raised by Loosemore $\& \mathrm{Lee}^{44}$ : the principal language of the main contractor may not be the principal language on site. Obviously, there are comprehension concerns if a manager and employee do not share the same first language. Verbal communication should be used in conjunction with non-verbal methods. Care should be taken not to try to communicate too much information at one time. It is important to try to keep messages fresh by delivering information in different ways and making it relevant to the tasks that the workforce undertakes. The person delivering the message should be trained and have the competences needed to communicate effectively. It is also essential to take every precaution to ensure that the employee understands the message conveyed. This aspect is developed further by Bust et $a l .{ }^{45}$ and Tutt et al. ${ }^{46}$

\section{Develop competent supervisors}

Supervisors at the OP were identified as the key individuals in the communication process, as well as the need for them to have the necessary competences, both technical and interpersonal, to increase the effectiveness and impact of health and safety messages:

Contractors agreed that supervision was an issue for safety. They said: 'Well, what we need to do is establish the general level of supervisor competence generally... and... to start training them to a consistent level, particularly in how to communicate toolbox talks, simple communications each day and the importance of supervision. And finally they need to be visible.' There were varied levels of competence, so the contractors then created themselves the supervisor safety leadership course. (Senior ODA staff)

Current literature supports the view that supervisors are at the frontline of safety. Serpell $\&$ Ferrada $^{47}$ note that supervisors serve a critical function on construction sites. From a survey conducted by Dingsdag et al. ${ }^{48}$ workers noted that supervisors are one of the most influential characters in the safety chain at site level. The role of construction supervisors in preventing fatalities was highlighted in research for the UK's Donaghy Inquiry Report in $2009 .{ }^{49}$ In summary, supervisors are often the channel for communication and also strongly influence the receiver's attention, comprehension and response. This applies to all projects. 


\section{Improve comprehension}

Typically, health and safety information is not difficult to understand. However, at the OP, interviewees stated that it was important that workers understood both what a role, procedure or initiative was, as well as why it was in place. Resources need to be devoted to this to ensure full understanding. There are several examples in the literature of how comprehension can be improved through the use of pictures, films and physical demonstrations. The literature has also evaluated these media of communication. In the UK setting, for people who have little or no understanding of English, additional effort needs to be made to ensure comprehension. Houts et al..$^{50}$ found that the use of pictures in transferring health information can increase comprehension and attention remarkably. Bust et al..$^{45}$ note that pictures and visual aids are commonly used on construction sites in a bid to improve workers' comprehension of safety issues. The use of pictures would initially appear to be an effective solution in the multicultural, multilingual environment that is construction. However, Bust et al. ${ }^{45}$ find that little thought is given to the design of visual aids in construction and there is no real validation of the effectiveness of these methods in communication. A person's cultural background may have a significant bearing on how they understand a visual aid.

On the Olympic site, the issue was addressed using translators as a comprehension aid where possible. Workers were given the opportunity to work in groups where at least one of the team members was bilingual. Comprehension isn't just about language and literacy; there's also an element of culture at play. A combined effort is needed by both the source and the receiver to ensure the message is getting through. In the C-HIP model, improving comprehension corresponds to receiver comprehension and is applicable to all projects.

Contractors on the Park ensured that each worker fully understood the rules of the environment before they set foot on site. Workers who were not comfortable in the environment and did not want to work safely often left:

Nobody gets on this site without having a full understanding of what the company think of safety. I think most of them buy into the culture and if some of them don't, then some of them leave. (Tier 1 works manager)

\section{Stimulate attitudes and beliefs}

It is important to understand the attitudes and beliefs of the workforce if you are going to influence them. For example, if people believe that safety glasses damage their vision, they will to try to avoid wearing them. Beliefs and attitudes are likely to vary between workers and should be determined and then addressed. Mohamed ${ }^{51}$ notes that, if health and safety decisions that have an impact on workers are to be effective, workers should be involved in making them. Other professions associated with healthy and safe construction have long established the benefit of user participation in job evaluation. Participatory ergonomics, for example, uses participative techniques and tools in projects with people who have a sufficient amount of knowledge and control to achieve desirable outcomes. ${ }^{52}$ In general, those who possess the most knowledge are the workers themselves. Participatory methods applicable to construction include postal bulletins, working groups, and management and staff groups. ${ }^{53}$ Workers' groups and health and safety forums involving several contractors were used as a viable means of communication at the OP.

Attitudes and beliefs are an important dimension for the receiver in the C-HIP model. Understanding workers' attitudes and beliefs is important for all projects. 


\section{Foster motivation to behave safely}

Even if design and procedural recommendations are in place, a lack of worker motivation to behave safely can have an adverse effect on site safety performance. ${ }^{48}$ At the site level, reasons for a lack of motivation are multifaceted and can often be influenced by higher-level decisions and actions. Eriksson \& Westerberg ${ }^{54}$ note that time, cost and quality are traditional indicators of construction project performance, and that focusing on them too much can lead to a poor work environment which is dangerous in terms of health and safety. More attention needs to be focused on the provisions that are made for workers in their direct environment and how they affect their motivation to behave safely. Several authors have highlighted the need to focus on worker participation and work environment to enhance project

performance. ${ }^{55-57}$ Positive change in the work environment can help eradicate the factors that demotivate employees, such as their perspectives on deficiencies in the workplace. ${ }^{58}$ There may be motivators for safe and unsafe behaviour on site. Motivators to behave unsafely and safely should be evaluated, addressed and publicised to ensure learning for the duration of a project and on future projects. Particular attention should be paid to the following:

- the time incurred by procedures

- the inconvenience of obtaining the correct materials or equipment

- how people are paid

- the pressure people are put under.

It is also important to recognise that different individuals are motivated by different things. Most are motivated to behave safely by a desire for self-preservation. However, they may be motivated to behave unsafely if the costs of safe behaviour are high. For example, they may be paid on the basis of piece rates, and perceive the safe way to do a job as time consuming, thereby limiting their output. Alternatively, some people may have underlying beliefs that motivate them to behave unsafely. If such a person comes to a site for a brief period, the opportunities to change these attitudes are limited. Therefore, it is important to motivate them in a different way and make sure that they understand the consequences of unsafe behaviour, ie they will be removed from the site. However, in the construction industry there is a habitual need for workers with specialised trades. There needs to be a focus on motivation for safety. Contractors can benefit from recognising what motivates workers to behave safely. This has benefits for both the worker and the site in terms of improved productivity and performance. A number of contractors at the OP recognised these motivational issues. When misdemeanours occurred, they chose to educate and train the workforce rather than simply move the problem to elsewhere in the industry. To get the message of safety across, we need to understand what motivates workers. Fostering motivation has a particular influence on receivers and is applicable to all projects.

\section{Foster an open, positive safety culture}

Safety culture is a sub-facet of organisational culture. Williams et al. ${ }^{59}$ define organisational culture as a notion that reflects shared behaviour, attitudes and values. In a safety culture, safety should be accepted as a number one priority. ${ }^{60}$ Therefore, safety needs to be the dominating factor of corporate culture and for that to be secured, worker involvement is crucial. There should be no ambiguity in spreading the organisational ideals of safety. There is often a direct correlation between workers' perceptions of how management views health and safety and actual safety performance. ${ }^{61}$ Fostering an open, positive safety culture within which workers feel able to communicate problems, without fear of retribution, is important. This can be achieved by adopting practices associated with behavioural safety ${ }^{61}$ and effective worker engagement. Engaged employees work with passion and feel a profound connection to 
their company. They drive innovation and move the organisation forward. ${ }^{62}$ Besides the moral and human objectives for worker engagement, it is essential that, where concerns are raised, feedback is given - workers need to know that they were listened to, if action had been taken and, if not, why not.

For all organisations, good practice in terms of dealing with the workforce can be implemented. The workforce is more likely to get involved with the health and safety process if they are engaged and feel that management cares for their wellbeing. It is also important that when workers raise issues that they receive feedback on what is done. When unsafe behaviour is observed, it is better to talk to the worker directly at the time, rather than report it for reprimand at a later date. Workers resent it if they are reported without being spoken to. Where this occurs it can cause problems, appearing to lead to 'us vs. them' cultures and less engagement. ${ }^{63}$ An open culture is especially important in the transient world of construction, where those involved in the culture may need to influence others. Culture will influence all stages of communication on all projects:

... seeing their peers challenge them about perhaps unsafe working practice or accepting an unsafe work environment, is the best motivator. Having your own peers challenge you, it makes you think. It really makes the manager's job that much easier because it doesn't mean they have to enforce the rules nearly as much because their peers are leading on safety; well that's a 'win-win' I think. (Assurance team member, CLM)

\section{Reward good behaviours}

At the OP, incentives and rewards were used to promote, encourage and reward safe behaviour. The views on reward and recognition in the literature are mixed. Sawacha et al. ${ }^{64}$ state that safety bonuses should always be paid, as they promote both safe and productive work. However, Duff ${ }^{65}$ found that while reward may affect initial behaviour, it has little impact on subsequent behaviours, implying that the effects are not long lasting. However, if reprimand is not handled correctly on site it may lead to worker irritation and have negative effects on behaviour. Lingard et al. ${ }^{66}$ also found mixed results for the effects of extrinsic manipulators such as rewards for behaviour. The reality is that, while workers are often thankful for incentives, their real reward is feedback and a boost to their morale:

I think the awards as well. I mean not so much, you know, having a prize, but it's always nice to know that your work is appreciated, especially the tradesmen. It's good to say 'You've done a good job.' I know you know you've done it, but to feel appreciated means a lot and it gives you a bit more morale so you can do even better. (Workers' focus group)

Contractors at the OP also acknowledged the importance of appropriate rewards for each audience. There was concern that if monetary rewards were given, workers would not report problems, which was, of course, contrary to the purpose of the reward. In effect, it was felt that some workers might not report things, thereby ensuring that the site would appear safer and they could get monetary rewards:

No, they shouldn't necessarily need to be rewarded, but you just have to watch where you go with it because, as I say, the $£ 50$ tokens was one of the first things we were doing and I think we kind of shied away from it in the end because, you shouldn't really have to reward somebody with money for doing their job, and doing it safely. But you've just got to watch...that somebody didn't report something in case they didn't get the year [without an incident]. (Tier 1 supervisor) 
Rewards for good behaviour are needed, but they don't always need to be monetary. If carefully applied, rewards will influence the behaviour of the receiver and motivator.

\section{Co-ordinate communication systems}

The ODA set out a strategy for communication in its Health, Safety and Environment standard, which all the contractors were contractually obliged to adhere to. Given the number of publications that cite the significance of communication in health and safety, ${ }^{*}$ it would appear imperative to facilitate its flow. The OP had various forums, such as the Health, Safety and Environment forum, some of which included workers, the goal of which was to have multidirectional, inclusive communication. The Park ran on a cycle of continual improvement and the regular communication meant that issues could be foreseen and any issues cascaded down to the workforce. The majority of people interviewed stated that communication was one of the best enablers for a safe environment and can easily be brought onto the next job.

A co-ordinated system of communication and fostering an appropriate culture for good practice sharing is essential for efficient construction. These systems also enable contractors to learn from each other and allow for the efficient dissemination of information in a complex organisational system. Procedures for informational cascade, within which all contractors and subcontractors take responsibility for passing information on, is necessary for fast and efficient communication. To foster the sharing of best practice, specific channels are needed to encourage the continual improvement of all participating contractors. A coordinated communication system will influence all aspects of communication, particularly feedback and review. It is recommended that large and more complex projects have greater co-ordination of communication.

\section{Stimulate cross-contractor learning}

Most projects involve several construction organisations, although rarely as many large contractors as at the OP. Multi-contractor projects present the opportunity for contractors (or subcontractors) to learn from each other and develop good health and safety practice from which the rest of the construction industry can benefit. Kale $\&$ Arditi ${ }^{69}$ investigated the relationship between contractors and subcontractors, and found that inter-organisational learning facilitated an open culture of social embeddedness and open communication. This type of relationship is essential given the often tight time constraints of construction projects. In this environment, collaboration can occur between contractors to develop new standards and practices.

The current study also showed that establishing such relationships can stimulate future learning and aid competitiveness in 'time poor' project environments. Communication systems to facilitate this include: strategic meetings that bring together company directors from the contractor organisations; meetings between key site management personnel to facilitate knowledge and good practice sharing; and cross-site visits to observe best practice.

Relationships between contractors will influence all aspects of communication, particularly feedback and review, leading to improved messages, sources and channels for future communication. In large and complex projects, because of the volume of contractors involved, there may be more opportunity for cross-contractor learning:

\footnotetext{
* See, for example, Brace et al., ${ }^{49}$ Donaghy ${ }^{67}$ and Gilbertson et al. ${ }^{68}$
} 
Yeah... they've been on major construction jobs - they've been on T5 [Heathrow Airport] so they just bring that ethos with them wherever they go. It's almost like educating other people in what they're doing as well. To them it's normal. When we came here first it was like 'Blimey - there's so much more to health and safety than we thought before on just the general major construction sites.' Probably if you went to the city, a lot of the big jobs there, it's the same sort of ethos. Hopefully contractors here, now, can take that back with them to their companies. (Tier 1 contractor)

\section{Review and learn}

Pre-construction reviews can help establish areas of concern that can be addressed later through toolbox talks. However, construction suffers from the blight of single-loop learning, where problems are dealt with on the spot but never fully addressed across the organisation. In effect, there is one-off learning on each project which is repeated from scratch over and over again. ${ }^{70}$ The effects of this can be detrimental especially in terms of health of safety, where the goal is prevention rather than cure. Reviewing and learning was noted as a key factor in the improvement of health and safety at the London 2012 construction site:

Reviewing and learning - recognising that things go wrong and things don't always go to plan, but it's what you do with that information when you get it and how you learn from it. Now they're very good at bouncing safety alerts round at people who go 'That's all very interesting,' but what do they actually do with them? So, they have a learning event, whether that's an incident, an accident, a good practice: how do they share it? So, getting them to recognise: (1) when they've had these learning events; and (2) then capitalise on the value that they can get out of it. It's getting them in a mind-set that says 'Somebody reviews it' and says 'Is this applicable to us?' Yes. What's it actually saying? What action do we need to take as a result of this? (Assurance team member, CLM)

Reviewing and learning will influence all aspects of communication, particularly feedback and review, leading to improved messages, sources and channels for future communication

\section{Provide assurance}

An assurance team was set up as part of the delivery partner, CLM. The team completed audits based on risk profiles and trends unique to a particular contractor or across the Park. Periodic assessments were completed to scrutinise self-monitoring reports and report back to the ODA. The assurance team also assessed trends and was kept informed of near misses via an accident tracker. ${ }^{19}$

The assurance team regarded on-site contractors as highly proficient and capable of working to contractually agreed standards. However, there was a general concern on site over the ability of contractors to self-regulate:

Yeah, and I think the industry's tried very hard. You know, so you go to Tier 1 contractor one and Tier 1 contractor two, because they really are very good contractors. They have those disciplines. They have those competences within there, you know, when you're looking at their management set-up. What they don't do is self-assure particularly well. (Senior CLM staff)

However, there is also a general concern in the industry over the effectiveness of selfregulation. Dawson et al. ${ }^{71}$ highlighted that there are several pitfalls associated with selfregulation, including the technical capacity of the contractor, knowledge, culture and general 
motivation. Self-regulation rarely works unless combined with other factors. ${ }^{30}$ A Health and Safety Executive report on preventing catastrophic events in construction ${ }^{68}$ identified the lack of independent checking as a major concern.

There was also a fear that contractors would become complacent about health and safety if they were left to self-regulate:

So they're an assurance. They're looking over my shoulder. I call them my conscience. (Tier 1 project director)

The regular inspections and monitoring by the CLM assurance team helped to ensure that standards were met, and also provided a vector for continual improvement and learning, which were essential to the flow of communication around the Park. Each of the assurance team members had dedicated sites, each of which they had an in-depth knowledge of, which meant they could make an effective judgment if the contractor had any queries. Moreover, the team members could pass on ideas and messages to contractors based on what they had learnt on other sites. The communication of ideas was facilitated by a close working relationship between the contractor and the assurance team member.

The presence of an assurance team member has an influence on all aspects of communication, particularly feedback and review, leading to improved messages, sources and channels. Independent assurance may be more achievable for larger projects, but should also be considered for smaller ventures.

\section{Statement of impact and significance, originality and impact of results}

The factors identified in this study to facilitate and enable the communication of health and safety in construction have been identified in previous studies, and in that sense what was found confirms previous work. However, previous research is much smaller in scale in terms of sample size and differentiation (ie single-site centric) and typically focuses on programmes run by smaller organisations. This study identified a much larger sample. The proliferation of ideas and methodologies outside of the OP, and the agreement of workers that messages were getting to them, highlights the novel aspect of this work. The fact that the facilitating factors were present at contractor sites on and outside the OP offers an applied example of the importance of each factor. Moreover, the work answers a fundamental question: Is it possible to transfer good ideas and initiatives from mega projects? The answer is yes, albeit in a modified way. The work is innovative because it gives an applied multi-site example that has not been wholly illustrated in previous work. However, the question still remains: How can we be certain that the programme on the Park was effective and that the systems put in place worked? The reality is that in terms of health and safety, the OP was 4.5 times more effective than the average construction site. The majority of interviewees identified the importance of communication in this health and safety achievement. The health and safety performance of the site, as well as the proliferation to external sites, highlights the validity of the performance of health and safety communication.

\section{Conclusions}

Mega projects offer an exciting opportunity for exploitative learning in the construction industry. Projects should no longer be viewed as unique. The OP construction project offers the perfect opportunity to capture lessons learnt. Overall, the OP construction programme demonstrated an efficient system of health and safety communication. However, the research team acknowledges the very significant influence of other factors, such as the elimination and 
reduction of hazards through design and preconstruction planning and supply chain management, along with more general effects of a concentration on health and safety culture and climate. Such aspects are covered by other research initiatives and are not specifically covered in these recommendations, except where they impact on communication.

The communication systems and processes in place at the OP were effective - they successfully transferred information from source to receiver. However, it is apparent that communication is only part of the system and simply transposing the basic communication processes to another context would not necessarily achieve the same outcomes. Many other pieces make up the jigsaw of successful health and safety performance, and the facilitating and enabling factors which support communication must also be recognised as bringing about its achievement.

Effective practice has been identified that the broader construction industry can apply to facilitate the communication of health and safety messages, although they need to be tailored to projects on a case-by-case basis. Many of the contractors on site highlighted that the initiatives used at the Park would be a veritable shopping list, where they could plan and choose the most suitable ones for their industry. The difference at the Park was the apparent ability to implement these initiatives effectively and consistently, and monitor them continually. The guided autonomy and the way standards were implemented highlights an important point that is applicable to the wider industry: it is not the standard that is important, but the specific way it is implemented, altered and maintained to suit the individual company:

I couldn't say anything we've done is innovative. The difference is that we've actually done it rather than talked about it and made it work. We made the supervisors' training work.

The visual standards - it's not innovative; it's just drawing pictures of what you want, but it's worked. We've simplified method statements. You could say that's innovative but, you know, no-one else in the industry has bothered to do it; and everybody agrees that it's one of those things that doesn't work; but nobody's prepared to put in the time or effort to change it and we did. (Senior ODA staff)

A new goal for industry is to learn and to use and develop what they have learnt and, of course, to review it.

\section{References}

1. National Institute for Occupational Safety and Health. Construction research at NIOSH: reviews of research programs of the National Institute for Occupational Safety and Health. Atlanta: NIOSH, 2008.

2. HSE. Work-related injuries and ill health in construction. 2011. www.hse.gov.uk/ statistics/industry/construction/index.htm. Viewed 13 November 2012.

3. Kadefors A. Institutions in building projects: implications for flexibility and change. Scandinavian Journal of Management 1995; 11 (4): 395-408.

4. Dubois A and Gadde L. The construction industry as a loosely coupled system: implications for productivity and innovation. Construction Management and Economics 2002; 20 (7): 621-631.

5. Barlow J, Jashapara A and Cohen M. Organisational learning and inter-firm partnering in the UK construction industry. The Learning Organization Journal 1998; 5: 86-98.

6. Davies T and Davies A. Building project capabilities: from exploratory to exploitative learning. Organization Studies 2000; 26 (9): 1601-1621.

7. Brady T, Davies A and Rush H. Learning to manage mega projects: the case of BAA 
and Heathrow Terminal 5. Paper for IRNOP VII Project Research Conference, Xi'an, China. 2006.

8. Lin J and Mills A. Measuring the occupational health and safety performance of construction companies in Australia. Facilities 2001; 19 (3/4): 131-138.

9. http://learninglegacy.independent.gov.uk. Viewed 12 November 2012.

10. Hide S A, Atkinson S, Pavitt T, Haslam R, Gibb A G F and Gyi D E. Causal factors in construction accidents. RR156. Sudbury: HSE Books, 2003. www.hse.gov.uk/research/ rrpdf/rr156.pdf. Viewed 13 November 2012.

11. Hartley R and Cheyne A. Safety culture in the construction industry. In: Dainty A (ed). Proceedings 25th Annual ARCOM Conference. 7-9 September 2009, Nottingham, UK: 1243-1252. www.arcom.ac.uk/-docs/proceedings/ar2009-1243-1252_Hartley_and_ Cheyne.pdf. Viewed 13 November 2012.

12. Abudayyeh O, Fredericks T K, Butt S E and Shaar A. An investigation of management's commitment to construction safety. International Journal of Project Management 2006; 24: 167-174.

13. Aksorn $\mathrm{T}$ and Hadikusumo B H W. Critical success factors influencing safety program performance in Thai construction projects. Safety Science 2008; 46 (4): 709-727.

14. Reese C and Eidson J. Handbook of OSHA construction safety and health. New York: Lewis Publishers, 1999.

15. Zohar D. Safety climate in industrial operations: theoretical and applied implications. Journal of Applied Psychology 1980; 65: 96-102.

16. Choudhry R M, Fang D P and Mohamed S. Developing a model of construction safety culture. Journal of Management in Engineering 2007; 23 (4): 207-212.

17. Cooper M D. Towards a model of safety culture. Safety Science 2000; 32 (6): 111-136.

18. Conzola V C and Wogalter M S. A communication-human information processing (C-HIP) approach to warning effectiveness in the workplace. Journal of Risk Research 2001; 4 (4): 309-322.

19. Bust P D. Delivering health and safety on the development of the London 2012 Olympic Park and Village: a review report for the Olympic Delivery Authority. London: Olympic Delivery Authority, 2011

20. King N. Using templates in the thematic analysis of text. In: Cassel C and Symon G (eds). Essential guide to qualitative methods in organisational research. London: Sage. 2004.

21. Cheyne A, Hartley R, Gibb A G and Finneran A. Talk the talk - walk the walk: an evaluation of Olympic Park safety initiatives and communication. Research report 12.1. Wigston: Institution of Occupational Safety and Health, 2012. www.iosh.co.uk/ publishedresearch. Viewed 13 November 2012.

22. Cheyne A, Finneran A, Hartley R and Gibb A G. Communication and action for a safer London 2012 Olympic and Paralympic Games. London: Olympic Delivery Authority, 2011. http://learninglegacy.independent.gov.uk/documents/pdfs/health-andsafety/260-communication-action-aw.pdf. Viewed 13 November 2012.

23. Cherns A B and Bryant D T. Studying the client's role in construction management. Construction Management and Economics 1984; 2 (2): 177-184.

24. Egan J. Rethinking construction. London: Department of Trade and Industry, 1998. www.constructingexcellence.org.uk/pdf/rethinking\%20construction/ rethinking_construction_report.pdf. Viewed 13 November 2012.

25. Gibb A G F and Isack F. Client drivers for construction projects: implications for standardisation. Engineering Construction \& Architectural Management 2001; 98 (1): 46-58. 
26. Briscoe G H, Dainty A R J, Millett S J and Neale R H. Client-led strategies for construction supply chain improvement. Construction Management and Economics 2004; 22 (2): 193-201.

27. Baxendale $\mathrm{T}$ and Jones $\mathrm{O}$. Construction design and management safety regulations In practice - progress on implementation. International Journal of Project Management 2000; 18: 33-40.

28. Lingard H and Rowlinson S M. Occupational bealth and safety in construction project management. London: Taylor and Francis, 2005.

29. Jeffrey J and Douglas I. Safety performance of the United Kingdom construction industry. In: Proceedings of the Fifth Annual Rinker International Conference Focusing on Construction Safety and Loss Control. University of Florida, Gainesville, FL, October 1994: 12-14.

30. HSE. Construction industry rises to London 2012 safety challenge. Press release NE/100/11. www.hse.gov.uk/press/2011/coi-ne-10011.htm. Viewed 13 November 2012.

31. Chartered Institute of Building. Leadership in the construction industry. Ascot: CIOB, 2007.

32. Dainty A R J, Cheng M I and Moore D R. Redefining performance measures for construction project managers: an empirical evaluation. Construction Management and Economics 2003; 21 (2): 209-218.

33. HSE. The health and safety of Great Britain: be part of the solution. www.hse.gov.uk/ strategy/strategy09.pdf. Viewed 13 November 2012.

34. Levitt R E and Samelson N M. Construction safety management. New York: McGrawHill, 1987.

35. Kay M A. Transportation megaproject procurement: benefits and challenges for PPPs and alternative delivery strategies, and the resulting implications for Crossrail. Master's thesis. Massachusetts Institute of Technology, 2004.

36. Lirtzman S I and Shuv-Ami A. Credibility of sources of communication on product safety hazards. Psychological Reports 1986; 58: 707-718.

37. Aakko E. Risk communication, risk perception, and public health. Wisconsin Medical Journal 2004; 103 (1):

38. Zou P X W, Zhang G and Wang J. Understanding the key risks in construction projects in China. International Journal of Project Management 2007; 25: 601-614.

39. Hare B, Cameron I and Duff A R. Exploring the integration of health and safety with pre-construction planning. Engineering, Construction and Architectural Management 2006; 13 (5): 438-450.

40. Duff $\mathrm{R}$ and Suraji A. Incorporating site management factors into design for a safe construction process. London: European Construction Institute, 2000.

41. HSE. Acting on responses to HSE's Discussion Document: Revitalising Health and Safety in Construction. London: HSE, 2003. www.hse.gov.uk/consult/disdocs/ dde20outcome.pdf. Viewed 13 November 2012.

42. Yi K J and Langford D. Scheduling-based risk estimation and safety planning for construction projects. Journal of Construction Engineering and Management 2006; 132:6(626).

43. Dainty A, Moore D and Murray M. Communication in construction theory and practice. London: Taylor and Francis, 2006.

44. Loosemore M and Lee P. Communication problems with ethnic minorities in the construction industry. International Journal of Project Management 2002; 20: 517-524.

45. Bust P D, Gibb A G F and Pink S. Managing construction health and safety: migrant workers and communicating safety messages. Safety Science 2007; 46 (4): 585-602.

46. Tutt D E, Dainty A R J, Gibb A G F and Pink S. Migrant construction workers and 
bealth \& safety communication. King's Lynn: Construction Industry Training Board, 2011. www.cskills.org/uploads/migrant-construction-workers-health-safetycommunication_tcm17-25018.pdf. Viewed 12 November 2012.

47. Serpell A and Ferrada X. A competency-based model for construction supervisors in developing countries. Personnel Review 2007; 36 (4): 585-602.

48. Dingsdag D P, Biggs H C and Sheahan V L. Understanding and defining OH\&S competency for construction site positions: worker perceptions. Safety Science 2008; 46 (4): 619-633.

49. Brace C, Gibb A G F, Pendlebury M and Bust P D. Health and safety in the construction industry: underlying causes of construction fatal accidents - External research. HSE Report. Norwich: HMSO, 2009. www.hse.gov.uk/construction/resources/phase2ext.pdf. Viewed 12 November 2012.

50. Houts P S, Doak C C, Doak L G and Loscalzo M J. The role of pictures in improving health communication: a review on attention, comprehension, recall, and adherence. Patient Education and Counseling 2006; 61 (2): 173-190.

51. Mohamed S. Safety climate in construction site environments. Journal of Construction Engineering and Management 2002; 128 (5): 375-384.

52. Wilson J R. Ergonomics and participation. In: Wilson J R and Corlett E N (eds). Evaluation of human work: a practical ergonomics methodology. 2 nd ed. London: Taylor and Francis, 1995: 1071-1096.

53. de Jong A M and Vink P. Participatory ergonomics applied in installation work. Applied Ergonomics 2002; 33: 439-448.

54. Eriksson P E and Westerberg M. Effects of cooperative procurement procedures on construction project performance: a conceptual framework. International Journal of Project Management 2011; 29: 197-208.

55. Weinstein M, Gambatese J and Hecker S. Can design improve construction safety?: assessing the impact of a collaborative safety-in-design processes. Journal of Construction Engineering and Management 2005; 131 (10): 1125-1134.

56. Cameron I and Duff A R. A critical review of safety initiatives using goal-setting and feedback. Construction Management and Economics 2007; 25: 495-508.

57. Rwamamara R. Planning the healthy construction workplace through risk assessment and design methods. Doctoral thesis. Civil, Mining, and Environmental Engineering, Luleå University of Technology, 2007.

58. Williamson A M, Feyer A M, Cairns D and Biancotti D. The development of a measure of safety climate: the role of safety perceptions and attitudes. Safety Science 1997; 25 (1-3): 15-27.

59. Williams A, Dobson P and Walters M. Changing culture: new organizational approaches. London: IPA, 1989.

60. Cullen W D. Report of the Official Inquiry into the Piper Alpha Disaster. London: HMSO, 1990.

61. DeJoy D M. Behaviour change versus culture change: divergent approaches to managing workplace safety. Safety Science 2005; 43 (2): 105-129.

62. Lockwood N R. Leveraging employee engagement for competitive advantage: HR's strategic role. SHRM Research Quarterly, 2007.

63. Biggs H C, Sheahan V L and Dingsdag D P. A study of construction site safety culture and implications for safe and responsive workplaces. The Australian Journal of Rehabilitation Counselling 2005; 11 (1): 1-8.

64. Sawacha E, Naoum S and Fong D. Factors affecting performance on construction sites. International Journal of Project Management 1999; 17 (5): 309-315.

65. Duff A R. Behaviour measurement for continuous improvement in construction safety 
and quality. In: Coble R J, Haupt T C and Hinze J (eds). The management of construction safety and health. Rotterdam: A A Balkema, 2000.

66. Lingard H, Gilbert G and Graham P. Improving solid waste reduction and recycling performance using goal setting and feedback. Construction Management and Economics 2001; 19 (8): 809-817.

67. Donaghy R. One death is too many. Inquiry into the underlying causes of construction fatal accidents. London: TSO, 2009.

68. Gilbertson A, Kappia J, Bosher L and Gibb A G F. Preventing catastrophic events in construction. RR834. Sudbury: HSE Books, 2011. www.hse.gov.uk/research/rrpdf/ rr834.pdf. Viewed 13 November 2012.

69. Kale $S$ and Arditi D. General contractors relationships with subcontractors: a strategic asset. Construction Management and Economics 2001; 19: 541-554.

70. Cushman R F and Myers J J. Construction law handbook. New York: Aspen Law and Business, 1999.

71. Dawson S, Willman P, Bamford M and Clinton A. Safety at work: the limits of selfregulation. Cambridge: Cambridge University Press, 1988. 